\title{
Locoregional Recurrence by Tumor Biology in Breast Cancer Patients after Preoperative Chemotherapy and Breast Conservation Treatment
}

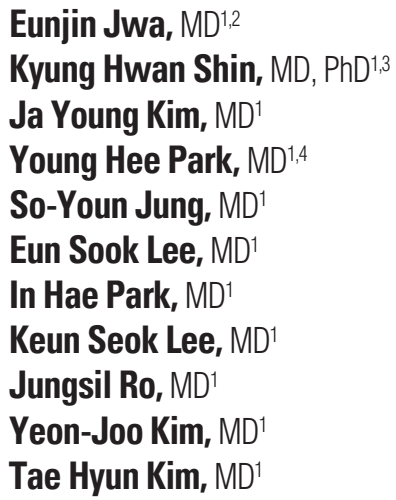

${ }^{1}$ Center for Breast Cancer, Research Institute and Hospital, National Cancer Center, Goyang, ${ }^{2}$ Department of Radiation Oncology, Soonchunhyang University Cheonan Hospital, Soonchunhyang University College of Medicine, Cheonan, ${ }^{3}$ Department of Radiation Oncology, Seoul National University College of Medicine, Seoul, ${ }^{4}$ Department of Radiation Oncology, Soonchunhyang University Hospital, Soonchunhyang University College of Medicine, Seoul, Korea

\section{Purpose}

The purpose of this study is to determine whether breast cancer subtype can affect locoregional recurrence (LRR) and ipsilateral breast tumor recurrence (IBTR) after neoadjuvant chemotherapy (NAC) and breast-conserving therapy (BCT).

\section{Materials and Methods}

We evaluated 335 consecutive patients with clinical stage II-III breast cancer who received NAC plus BCT from 2002 to 2009. Patients were classified according to six molecular subtypes: luminal A (hormone receptor $[\mathrm{HR}]+/ \mathrm{HER} 2-/ \mathrm{Ki}-67<15 \%, \mathrm{n}=113$ ), luminal B1 (HR+/HER2-/Ki-67 $\geq 15 \%, n=33)$, luminal B2 (HR+/HER2+, n=83), HER2 with trastuzumab (HER2[T+]) (HR-/HER2+/use of trastuzumab, $n=14)$, HER2 without trastuzumab (HER2[T-]) (HR-/HER2+, n=31), and triple negative (TN) (HR-/HER2-, n=61).

\section{Results}

After a median follow-up period of 7.2 years, 26 IBTRs and 37 LRRs occurred. The 5-year LRR-free survival rates were luminal A, 96.4\%; B1, 93.9\%; B2, 90.3\%; HER2(T+), 92.9\%; HER2(T-), 78.3\%; and TN, 79.6\%. The 5-year IBTR-free survival rates were luminal A, 97.2\%; B1, 93.9\%; B2, 92.8\%; HER2(T+), 92.9\%; HER2(T-), 89.1\%; and TN, 84.6\%. In multivariate analysis, HER2(T-) (IBTR: hazard ratio, 4.2; $p=0.04$ and LRR: hazard ratio, 7.6; $p<0.01$ ) and TN subtypes (IBTR: hazard ratio, 6.9; $p=0.01$ and LRR: hazard ratio, 8.1; $p<0.01$ ) were associated with higher IBTR and LRR rates. A pathologic complete response (pCR) was found to show correlation with better LRR and a tendency toward improved IBTR controls in TN patients (IBTR, $p=0.07$; LRR, $p=0.03$ ).

\section{Conclusion}

The TN and HER2(T-) subtypes predict higher rates of IBTR and LRR after NAC and BCT. A PCR is predictive of improved IBTR or LRR in TN subtype.
Correspondence: Kyung Hwan Shin, MD, PhD Department of Radiation Oncology, Seoul National University College of Medicine, 103 Daehak-ro, Jongno-gu, Seoul 03080, Korea Tel: $82-2-2072-2524$

Fax: 82-2-765-3317

E-mail: radiat@snu.ac.kr

Received November 24, 2015

Accepted January 28, 2016

Published Online February 18, 2016

\section{Key words}

Breast neoplasms, Molecular subtype, Neoadjuvant chemotherapy, Ipsilateral breast tumor recurrence, Local neoplasm recurrence 


\section{Introduction}

Neoadjuvant chemotherapy (NAC) has generally been used in treatment of locally advanced and inflammatory breast cancer, but its use is increasing for earlier stages of the disease [1-3]. The number of patients who are candidates for breast conserving treatment $(\mathrm{BCT})$ increases with the use of NAC, which downsizes tumors, facilitating $B C T$ in patients who would otherwise require mastectomy [2,4]. Several clinical trials have reported equivalent impacts of neoadjuvant versus adjuvant chemotherapy on survival $[2,3]$. The locoregional recurrence (LRR) rate was also acceptably low in patients treated with NAC followed by breast conserving surgery (BCS) and radiotherapy (RT) $[2,4,5]$.

DNA microarray analysis of gene expression profiles has divided breast cancer into distinct molecular subtypes with different clinical outcomes and responses to treatment, including estrogen receptor (ER)-positive/luminal, basallike, and HER2-positive subtypes [6,7]. However, DNA microarray analysis has challenges for wide use in routine clinical care, determination of molecular subtypes based on clinically available immunohistochemical (IHC) markers such as hormone receptor (HR) and HER2 status has been considered and validated as a more practical approach to identification of the corresponding subgroups based on gene expression profiling $[8,9]$. It has been demonstrated that different molecular subtypes can predict LRR in addition to survival and distant metastasis (DM) in the adjuvant setting [10-12]. However, the impact of molecular subtypes on ipsilateral breast tumor recurrence (IBTR) and LRR in patients who undergo NAC warrants further investigation.

Therefore, the current study was conducted to evaluate whether molecular subtypes can identify patients at high risk for IBTR and LRR following NAC and BCT.

\section{Materials and Methods}

This was a single-institution retrospective review of an Institutional Review Board-approved prospective breast cancer database. A total of 335 consecutive patients with nonmetastatic breast cancer who underwent NAC followed by BCS and RT from 2002 to 2009 were identified. Before initiation of NAC, all patients had been clinically staged according to the sixth edition of the American Joint Committee on Cancer (AJCC) guidelines. Clinical stages were evaluated by physical examination, ultrasonography, fluorodeoxyglucosepositron emission tomography (PET)/ computed tomography $(\mathrm{CT})$, and chest CT. Clinicopathological data were recorded, including age, menopause status, cT stage, cN stage, pathological tumor size, number of lymph nodes (LNs) identified pathologically, histological type, histological grade, ER, progesterone receptor (PR), HER2, and Ki-67 status. NAC consisted of anthracycline-based (doxorubicin $60 \mathrm{mg} / \mathrm{m}^{2}$ and cyclophosphamide $600 \mathrm{mg} / \mathrm{m}^{2}$ every 3 weeks for four cycles, $n=150$ ), taxane-based (docetaxel $75 \mathrm{mg} / \mathrm{m}^{2}$ and capecitabine $1,000 \mathrm{mg} / \mathrm{m}^{2}$ orally twice daily on days 1-14 every 3 weeks for four cycles, $n=85$; paclitaxel $80 \mathrm{mg} / \mathrm{m}^{2}$ followed by gemcitabine $1,200 \mathrm{mg} / \mathrm{m}^{2}$ on days 1 and 8 every 3 weeks for four cycles, $n=27$ ), or combined anthracyclinetaxane-based therapy (doxorubicin $60 \mathrm{mg} / \mathrm{m}^{2}$ and cyclophosphamide $600 \mathrm{mg} / \mathrm{m}^{2}$ every 3 weeks for four cycles followed by docetaxel $100 \mathrm{mg} / \mathrm{m}^{2}$ every 3 weeks for four cycles, $\mathrm{n}=73)$. A total of 245 patients $(73.1 \%)$ were treated in one of the two prospective institutional clinical trials. Full details of the regimens used have been previously reported $[13,14]$. NAC regimen for the remainder was chosen at physician's discretion. In the BCS procedure, residual primary tumors were excised, and clear margins to healthy tissues were determined from frozen biopsy specimens. However, five patients with persistent positive resection margins in the final pathology reports declined further surgical resection. No further revision surgery was attempted in 30 patients with close resection margins $(<2 \mathrm{~mm})$. Standard level I and II axillary LN dissections were performed in all except 14 patients who underwent sentinel LN biopsy without axillary dissection. No residual tumor or only carcinoma in situ in both primary breast tumor and LNs was considered pathologic complete response (pCR). Following BCS, RT was performed with tangential fields at a median dose to the breast of 50.4 Gy in 28 fractions over 5.5 weeks in all patients. All patients received an electron boost to the tumor bed with a median dose of $10 \mathrm{~Gy}$ in five fractions. Supraclavicular nodal RT was delivered in 318 patients (median dose, 45 Gy in 25 fractions). Internal mammary nodal RT was administered at a median dose of $55 \mathrm{~Gy}$ to only seven patients with pre-NAC initial PET-positive internal mammary LNs. Adjuvant hormone suppression therapy was offered to all patients with ER-positive or PR-positive tumors. Some patients showed changes in ER and PR expression before and after NAC, but hormonal suppression therapy was administered to all patients whose tumors were ER- or PR-positive in one or more tests. Following RT, trastuzumab was administered for 1 year to 36 patients with HER2-positive tumors.

An IHC assay was used to evaluate the expression of the ER, PR, HER2, and Ki-67 markers in pretreatment core biopsies. ER and PR positivity were defined using the Allred score when strong nuclear staining was observed in at least $3 / 8$ tumor cells examined [15]. ER and PR status were categorized as HR-positive when ER or PR staining was positive, and as HR-negative when ER and PR staining were negative. 
Immunostaining for HER2 was considered positive in the case of strong (3+) membranous staining in at least $10 \%$ of tumor cells, or in the case of $2+$ with unequivocal amplification by fluorescence in situ hybridization [16]. For evaluation of Ki-67, areas with the highest Ki-67 staining were examined [17]; $15 \%$ was used as the cut-off value for Ki-67 to dichotomize the patients $[18,19]$. According to the IHC features on core biopsies before NAC, patients were classified according to IHC-based molecular subgroups as follows: luminal A (HR+/HER2-/Ki-67 < 15\%), luminal B1 (HR+/HER2-/ Ki-67 $\geq 15 \%$ ), luminal B2 (HR+/HER2+), HER2 (HR/HER2+), and triple negative (TN) (HR-/HER2-). In this study, the HER2 group, which is known as an unfavorable feature, was divided into two subtypes based on the use of trastuzumab. The final six groups were as follows: luminal A, luminal B1, luminal B2, HER2 with trastuzumab (HER2[T+]), HER2 without trastuzumab (HER2[T-]), and TN.

The primary endpoints were IBTR and LRR. IBTR was defined as recurrent disease in the ipsilateral breast. LRR was defined as recurrent disease in the ipsilateral breast, chest wall or axillary, supraclavicular, infraclavicular, or internal mammary LNs. All IBTRs and LRRs were considered events, regardless of whether they were the first site of failure versus occurred with or after DM. Patients who did not experience IBTR or LRR were censored at the last follow-up or at the time of death. Distributions of the clinical factors among groups were compared using the Kruskal-Wallis test for continuous variables and the chi-square test for categorical variables. Actuarial rates of IBTR and LRR were calculated using the Kaplan-Meier method, and differences between groups were compared using the two-sided log-rank test. Logistic regression was used to evaluate the association between covariates of interest and the probability of IBTR or LRR. Multivariate analyses were performed using the Cox proportional hazards model. All calculations were performed using SPSS ver. 18.0 (SPSS Inc., Chicago, IL). Two-tailed p-values $<0.05$ were considered statistically significant.

\section{Results}

Clinicopathological characteristics by subtype are summarized in Table 1. The median age was 48 years (range, 28 to 76 years). Significant differences in the distribution of histological type, histological grade, resection margin status, and response to NAC were observed among subtypes. In evaluation of the response to NAC, we noted a difference $(\mathrm{p}<0.01)$ in $\mathrm{pCR}$ rates with a lower percentage of patients in the luminal A $(10.6 \%)$ and B1 $(6.1 \%)$ subgroups compared with patients in the HER2(T-) (35.5\%), and TN (23.0\%) subgroups.

The median follow-up period was 7.2 years (range, 0.7 to 11.6 years). Twenty-six IBTRs, 15 regional recurrences, $67 \mathrm{DMs}$, and 56 deaths occurred during follow-up (Table 2). The 5-year LRR-free survival rates in the subtypes were as follows: luminal A, 96.4\%; B1, 93.9\% ; B2, 90.3\%; HER2(T+), 92.9\%; HER2(T-), 78.3\%; and TN, 79.6\% (Fig. 1A). Compared with the luminal A subtype, significantly higher LRR rates were observed for the luminal B2, HER2(T-), and TN subtypes ( $\mathrm{p}=0.02, \mathrm{p}<0.01$, and $\mathrm{p}<0.01$, respectively). The 5 -year IBTR-free survival rates in the subtypes were as follows: luminal A, 97.2\%; B1, 93.9\%; B2, 92.8\%; HER2(T+), 92.9\%; HER2(T-), 89.1\%; and TN, 84.6\% (Fig. 1B). The HER2(T-) and TN subtypes had significantly higher rates of IBTR compared with the luminal A subtype ( $p=0.04$ and $p<0.01$, respectively). Despite the same unfavorable molecular markers with HER2(T-), HER2(T+) subtype showed no difference in IBTR and LRR rates compared with the luminal A subtype. The 5-year DM-free and disease-free survival (DFS) rates were as follows: luminal A, 90.2\%; B1, 75.6\%; B2, 83.0\%; HER2(T+), 85.7\%; HER2(T-), 76.6\%; and TN, 75.4\% (Fig. 1C) and luminal A, 88.4\%; B1, 75.6\%; B2, 81.9\%; HER2(T+), 85.7\%; HER2(T-), 70.0\%; and TN, 72.1\% (Fig. 1D), respectively.

The clinicopathological variables associated with IBTR and LRR were analyzed by univariate and multivariate analyses (Table 3). In univariate analysis, the factors affecting IBTR development included the TN subtype $(\mathrm{p}<0.01)$, poorly differentiated tumors $(\mathrm{p}=0.03)$, and clinical T3-4 stage $(\mathrm{p}<0.01)$. Luminal B2 subtype $(\mathrm{p}=0.03)$, HER2(T-) subtype $(\mathrm{p}<0.01)$, TN subtype $(\mathrm{p}<0.01)$, poorly differentiated tumor $(\mathrm{p}=0.01)$, and clinical T3-4 stage $(\mathrm{p}<0.01)$ were also associated with lower LRR-free survival rates. In the multivariate model, the HER2(T-) subtype, TN subtype, and clinical T3-4 stage affected the development of both IBTR and LRR. Compared with the luminal A subtype, the HER2(T-) and TN subtypes were potent factors affecting IBTR/LRR, with hazard ratios of $4.2(\mathrm{p}=0.04) / 7.6(\mathrm{p}<0.01)$ and $6.9(\mathrm{p}=0.01) / 8.1(\mathrm{p}<0.01)$, respectively (Table 3 ). Notably, a pCR after NAC was not associated with the development of IBTR $(\mathrm{p}=0.39)$ or LRR $(\mathrm{p}=0.65)$. Patients of the HER2(T+) subtype had significantly lower hazard ratios for IBTR and LRR compared with HER2(T-) patients.

In the analysis of IBTR and LRR according to $\mathrm{pCR}$ versus non-pCR after NAC, patients of the TN subtype who failed to achieve $\mathrm{pCR}$ showed a significantly higher LRR $(\mathrm{p}=0.03)$ (Fig. $2 \mathrm{~A})$ rate and a trend toward higher IBTR $(\mathrm{p}=0.07)$ (Fig. 2B) rate compared with those who achieved a pCR. However, among patients of the non-TN subtypes, including HER2(T-), no significant effect of a pCR on either LRR $(\mathrm{p}=0.52)$ (Fig. 2A) or IBTR ( $\mathrm{p}=0.41)$ (Fig. 2B) was observed. 
Table 1. Distribution of clinical and pathological characteristics by molecular subtype

\begin{tabular}{|c|c|c|c|c|c|c|c|}
\hline Variable & $\begin{array}{l}\text { Luminal A } \\
\qquad(\mathrm{n}=113)\end{array}$ & $\begin{array}{l}\text { Luminal B1 } \\
\qquad(\mathrm{n}=33)\end{array}$ & $\begin{array}{l}\text { Luminal B2 } \\
\qquad(\mathrm{n}=83)\end{array}$ & $\begin{array}{c}\text { HER2 }(\mathrm{T}+) \\
(\mathrm{n}=14)\end{array}$ & $\begin{array}{c}\text { HER2(T-) } \\
\quad(n=31)\end{array}$ & $\begin{array}{c}\text { Triple } \\
\text { negative }(n=61)\end{array}$ & p-value \\
\hline \multicolumn{8}{|l|}{ Age (yr) } \\
\hline$\leq 40$ & $31(27.4)$ & $9(27.3)$ & $17(20.5)$ & $2(14.3)$ & $4(12.9)$ & $15(24.6)$ & 0.51 \\
\hline$>40$ & $82(72.6)$ & $24(72.7)$ & $66(79.5)$ & $12(85.7)$ & $27(87.1)$ & $46(75.4)$ & \\
\hline Post-menopause & $37(32.7)$ & $9(27.3)$ & $31(37.3)$ & $6(42.9)$ & $15(48.4)$ & $19(31.1)$ & 0.47 \\
\hline \multicolumn{8}{|l|}{ cT stage } \\
\hline cT1-2 & 105 (92.9) & $29(87.9)$ & $73(88.0)$ & $11(78.6)$ & $27(87.1)$ & $50(82.0)$ & 0.16 \\
\hline cT3-4 & $8(7.1)$ & $4(12.1)$ & $10(12.0)$ & $3(21.4)$ & $4(13.0)$ & $11(18.0)$ & \\
\hline \multicolumn{8}{|l|}{ cN stage } \\
\hline cN0 & $2(1.8)$ & 0 & $1(1.2)$ & 0 & 0 & 0 & 0.28 \\
\hline cN1 & $66(58.4)$ & $14(42.4)$ & $41(49.4)$ & $4(28.6)$ & $20(64.5)$ & $27(44.3)$ & \\
\hline cN2-3 & $45(39.8)$ & $19(57.6)$ & $41(49.4)$ & $10(71.4)$ & $11(35.5)$ & $34(55.8)$ & \\
\hline \multicolumn{8}{|l|}{ cStage } \\
\hline II & $64(56.6)$ & $13(39.4)$ & $38(45.8)$ & $4(28.6)$ & $18(58.1)$ & $23(37.7)$ & 0.06 \\
\hline III & $49(43.4)$ & $20(60.6)$ & $45(54.2)$ & $10(71.4)$ & $13(41.9)$ & $38(62.3)$ & \\
\hline \multicolumn{8}{|l|}{ ypT } \\
\hline урТ0 & $17(15.0)$ & $3(9.1)$ & $22(26.5)$ & $5(35.7)$ & $12(38.7)$ & $19(31.1)$ & 0.01 \\
\hline урТ1 & $61(54.0)$ & $12(36.4)$ & $39(47.0)$ & $6(42.9)$ & $13(41.9)$ & $27(44.3)$ & \\
\hline урТ2-3 & $35(31.0)$ & $18(54.5)$ & $22(26.5)$ & $3(21.4)$ & $6(19.4)$ & 15 (24.6) & \\
\hline \multicolumn{8}{|l|}{ ypN } \\
\hline ypN0 & 27 (23.9) & $14(42.4)$ & $33(39.8)$ & $4(28.6)$ & $17(54.8)$ & $33(54.1)$ & $<0.01$ \\
\hline ypN1 & $56(49.6)$ & 7 (21.2) & $26(31.3)$ & $6(42.8)$ & $10(32.3)$ & $17(27.9)$ & \\
\hline ypN2-3 & $30(26.5)$ & $12(36.4)$ & $24(28.9)$ & $4(28.6)$ & 4 (12.9) & $11(18.0)$ & \\
\hline $\mathrm{pCR}$ & 12 (10.6) & $2(6.1)$ & $16(19.3)$ & $3(21.4)$ & $11(35.5)$ & $14(23.0)$ & $<0.01$ \\
\hline \multicolumn{8}{|l|}{ Histology } \\
\hline IDC & 105 (92.9) & $27(81.8)$ & $80(96.4)$ & $13(92.9)$ & $31(100)$ & $61(100)$ & $<0.01$ \\
\hline Others & $8(7.1)$ & $6(18.2)$ & $3(3.6)$ & $1(7.1)$ & 0 & 0 & \\
\hline \multicolumn{8}{|l|}{ Histological grade } \\
\hline Well, moderate & $84(74.3)$ & $11(33.3)$ & $49(59.0)$ & $6(42.9)$ & $16(51.6)$ & $30(49.2)$ & $<0.01$ \\
\hline Poor & $29(25.7)$ & $22(66.7)$ & $34(41.0)$ & $8(57.1)$ & $15(48.4)$ & $31(50.8)$ & \\
\hline \multicolumn{8}{|l|}{ Resection margin } \\
\hline Negative & $100(88.5)$ & $27(81.8)$ & $70(84.3)$ & $14(100)$ & $29(93.5)$ & $60(98.4)$ & $<0.01$ \\
\hline Close, positive & 13 (11.5) & $6(18.2)$ & $13(15.7)$ & 0 & $2(6.5)$ & $1(1.6)$ & \\
\hline
\end{tabular}

Values are presented as number (\%). HER2(T+), HER2 with trastuzumab; HER2(T-), HER2 without trastuzumab; pCR, pathologic complete response; IDC, invasive ductal carcinoma.

\section{Discussion}

Breast cancer is now regarded as a biologically heterogeneous disease comprising different molecular subtypes, each with a different prognosis and response to treatment [10-12]. These subtypes, including luminal, HER2, and basal-like, can be defined by gene expression profiling $[6,20,21]$ or approximations to this classification using IHC [8,9]. Clinicians should consider these features for proper assessment of the relevant evidence and decide on an appropriate therapeutic course of action. In a series of women with clinical stage II-
III breast cancer who underwent NAC and BCT, we found that molecular subtypes showed correlation with different rates of IBTR and LRR. The TN and HER2(T-) subtypes had worse outcomes with significantly higher IBTR and LRR rates than those of other subtypes despite excellent tumor responses to NAC.

Several authors have examined the impact of molecular subtype on LRR in different patient populations. Nguyen et al. [10] evaluated 793 patients treated with BCT as a first-line intervention. After a median follow-up period of 70 months, the 5-year LRR rate was $0.8 \%$ for luminal A, 8.4\% for HER2, and $7.1 \%$ for basal subtypes. Arvold et al. [22] also evaluated 
Table 2. Patterns of failure

\begin{tabular}{|c|c|c|c|c|c|c|c|}
\hline Variable & $\begin{array}{l}\text { Luminal A } \\
(n=113)\end{array}$ & $\begin{array}{l}\text { Luminal B1 } \\
\qquad(\mathrm{n}=33)\end{array}$ & $\begin{array}{l}\text { Luminal B2 } \\
\qquad(\mathrm{n}=83)\end{array}$ & $\begin{array}{l}\text { HER2(T+) } \\
\qquad(\mathrm{n}=14)\end{array}$ & $\begin{array}{l}\text { HER 2(T-) } \\
\quad(n=31)\end{array}$ & $\begin{array}{c}\text { Triple } \\
\text { negative }(n=61)\end{array}$ & $\begin{array}{c}\text { Total } \\
(n=335)\end{array}$ \\
\hline Any recurrence & $16(14.2)$ & $9(27.3)$ & $21(25.3)$ & $2(14.3)$ & $9(29.0)$ & $20(32.8)$ & $77(23.0)$ \\
\hline LRR & $4(3.5)$ & $3(9.1)$ & $10(12.0)$ & $1(7.1)$ & $6(19.4)$ & $13(21.3)$ & $37(11.0)$ \\
\hline IBTR & $3(2.7)$ & $3(9.1)$ & $7(8.4)$ & $1(7.1)$ & $3(9.7)$ & $9(14.8)$ & $26(7.8)$ \\
\hline Regional recurrence & $1(0.9)$ & $2(6.1)$ & $3(3.6)$ & 0 & $3(9.7)$ & $6(9.8)$ & $15(4.5)$ \\
\hline Axillary lymph node & 0 & 2 & 2 & 0 & 0 & 0 & 4 \\
\hline SCLN & 0 & 0 & 0 & 0 & 2 & 3 & 5 \\
\hline IMLN & 1 & 1 & 1 & 0 & 2 & 4 & 9 \\
\hline Distant metastasis & $14(12.4)$ & $8(24.2)$ & $18(21.7)$ & $2(14.3)$ & $7(22.6)$ & $18(29.5)$ & $67(20.0)$ \\
\hline
\end{tabular}

Values are presented as number (\%). HER2(T+), HER2 with trastuzumab; HER2(T-), HER2 without trastuzumab; LRR, locoregional recurrence; IBTR, ipsilateral breast tumor recurrence; SCLN, supraclavicular lymph node; IMLN, internal mammary lymph node.

differences in LRR according to subtype in patients undergoing BCT as initial treatment. These patients were classified based on receptor status as well as nuclear grade, with subgroups defined as luminal A (HR+/HER2-/grade 1-2), luminal B (HR+/HER2-/grade 3), luminal HER2 (HR+/ HER2+), HER2 (HR-/HER2+), and TN (HR-/HER2-). The 5-year LRR rates were $0.8 \%$ for luminal A, $10.8 \%$ for HER2, and $6.7 \%$ for TN subtypes. In contrast to our study, both of these studies were limited to patients undergoing initial surgery [10,22]. Vargo et al. [23] analyzed 331 patients receiving NAC plus BCT or mastectomy. After a median follow-up period of 43 months, 5-year LRR rates were 3.8\%, 1.3\%, and $4.2 \%$ for luminal A, HER2, and basal subtypes, respectively. The molecular subtype and pCR predicted DM, DFS, and overall survival (OS). Meyers et al. [24] used constructed molecular subtypes for prediction of LRR in 149 patients. Only patients who received NAC were included; however, patients underwent BCT or mastectomy. After a median follow-up period of 55 months, a higher rate of LRR in patients with basal $(14 \%)$ versus luminal $(4 \%)$ or HER2 $(5 \%)$ tumors was reported. By evaluating only the 49 patients who underwent BCT, no LRR events were observed in the luminal or HER2 groups, while $8 \%$ of the basal group developed LRR. Most recently, Caudle et al. [25] analyzed the clinicopathological data from 595 patients who received NAC and BCT. After a median follow-up period of 64 months, the 5-year LRR-free survival rates were found to vary by subtype: HR+/HER2-, 97.0\%; HR+/HER2+, 95.9\%; HR-/HER2+, 86.5\%; and HR-/HER2-, 89.5\% ( $\mathrm{p}=0.001)$. The pCR was associated with lower LRR rate.

There appears to be several critical differences between our analysis and previously published data. First, our data encompassed a homogeneous group of patients with clinical stage II-III breast cancer who underwent NAC followed by
BCT at a single institution, compared with the results from patients treated with NAC followed by BCT or mastectomy. To the best of our knowledge, the current study is unique in its analysis of the impact of molecular subtypes on IBTR and LRR in patients who underwent NAC followed by only BCT, which could be associated with the concerns regarding a higher LRR rate compared with mastectomy. Most previous studies have focused on DFS, OS, or LRR alone [23,26-28]. Second, we analyzed patients who were treated recently, between 2002 and 2010. Other series included patients treated since 1991 or 1998 [10,24]. Inclusion of patients from previous treatment eras may yield higher rates of LRR compared with those treated more recently due to several factors. The evolution of systemic therapy has resulted in better local control and better outcomes on systemic recurrence. The use of modern radiation techniques and the evolution of breast imaging may have an impact on the rates of IBTR and LRR. Third, we included 36 patients treated with trastuzumab, of whom 14 HER2(T+) patients had a better local outcome compared with HER2(T-) patients. Five-year IBTR- and LRR-free survival rates were $92.9 \%$ versus $89.1 \%$ and $92.9 \%$ versus $78.3 \%$ in HER2(T+) versus HER2(T-), respectively. This result suggests that the use of trastuzumab could alter the impact of the molecular subtype on local outcome in HER2 subtype patients. This might be useful information in the consideration of trastuzumab in HER2 subtype patients.

Last, we found that a pCR to NAC had no impact on locoregional outcomes in any patients of non- $\mathrm{TN}$ groups. In TN patients, however, a pCR was associated with excellent IBTR and LRR control. The association between the extent of response to NAC and prognosis has been examined $[3,5,23,25-27]$. The best relative DFS $[3,26,28]$, as well as DM-free survival, and OS $[23,27]$ was observed in those who achieved a pCR. Min et al. [5] reported that a pCR to NAC 

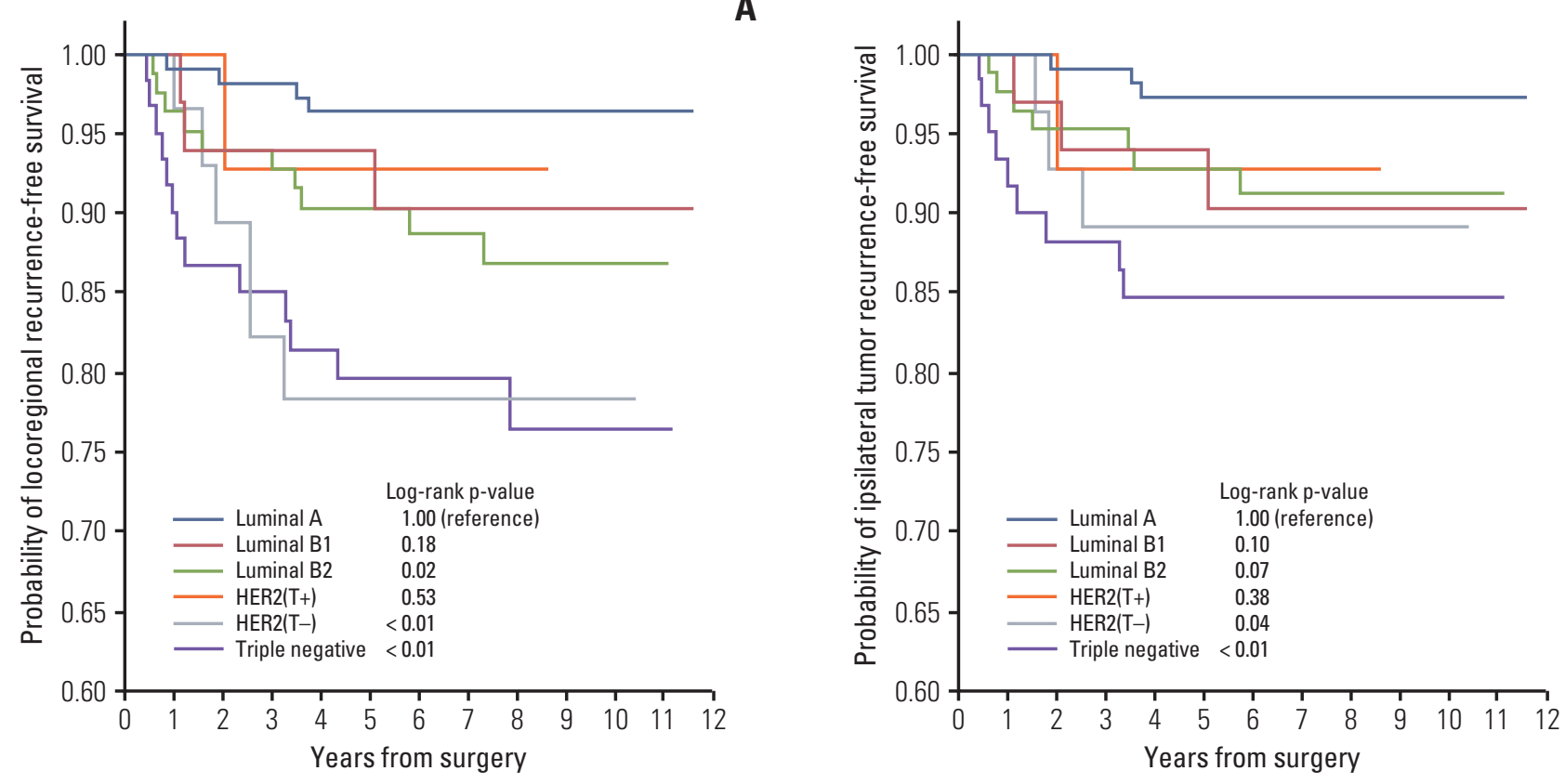

C

D
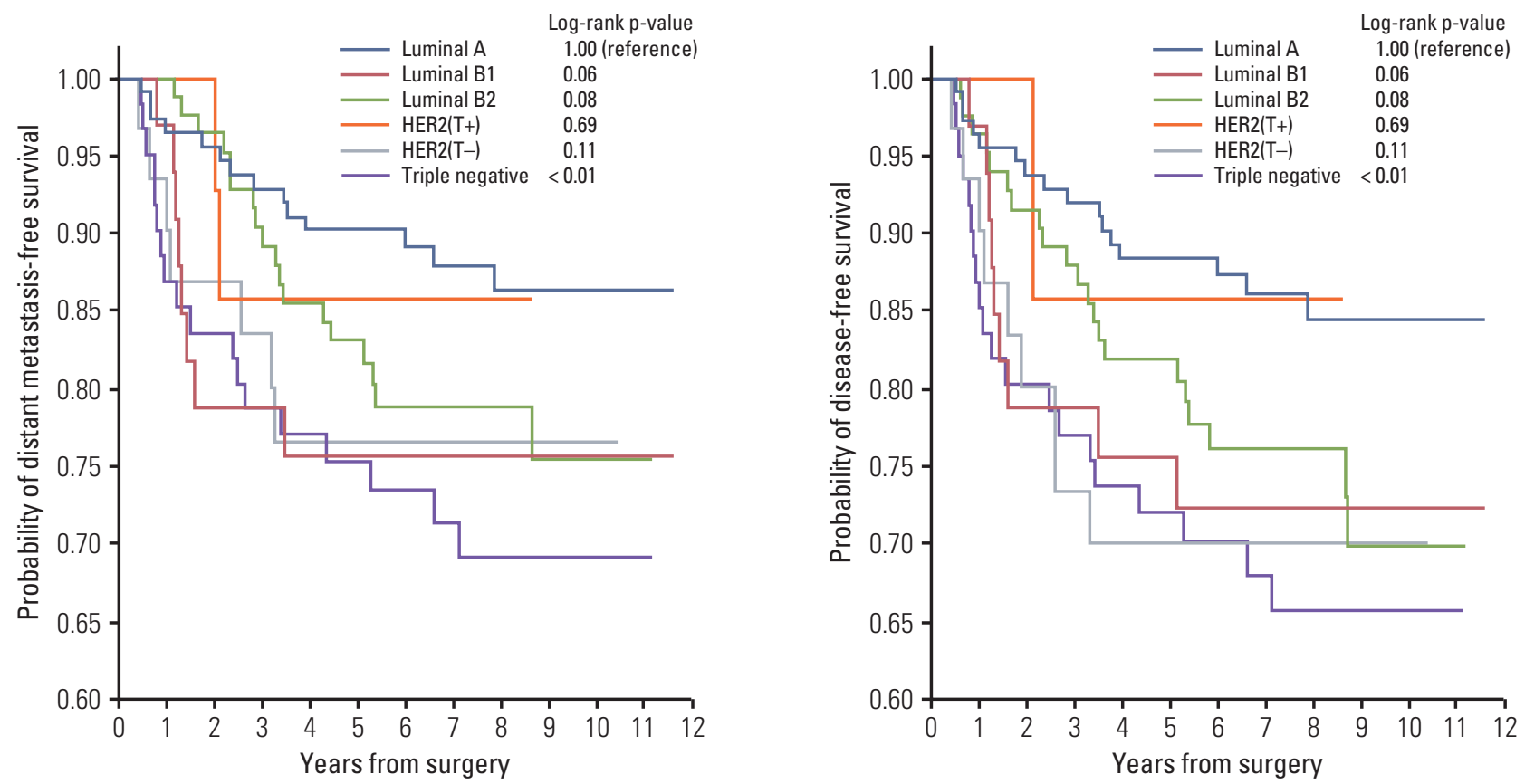

Fig. 1. Kaplan-Meier plots of locoregional recurrence-free survival (A), ipsilateral breast tumor recurrence-free survival (B), distant metastasis-free survival (C), and disease-free survival (D) according to molecular subtype. 


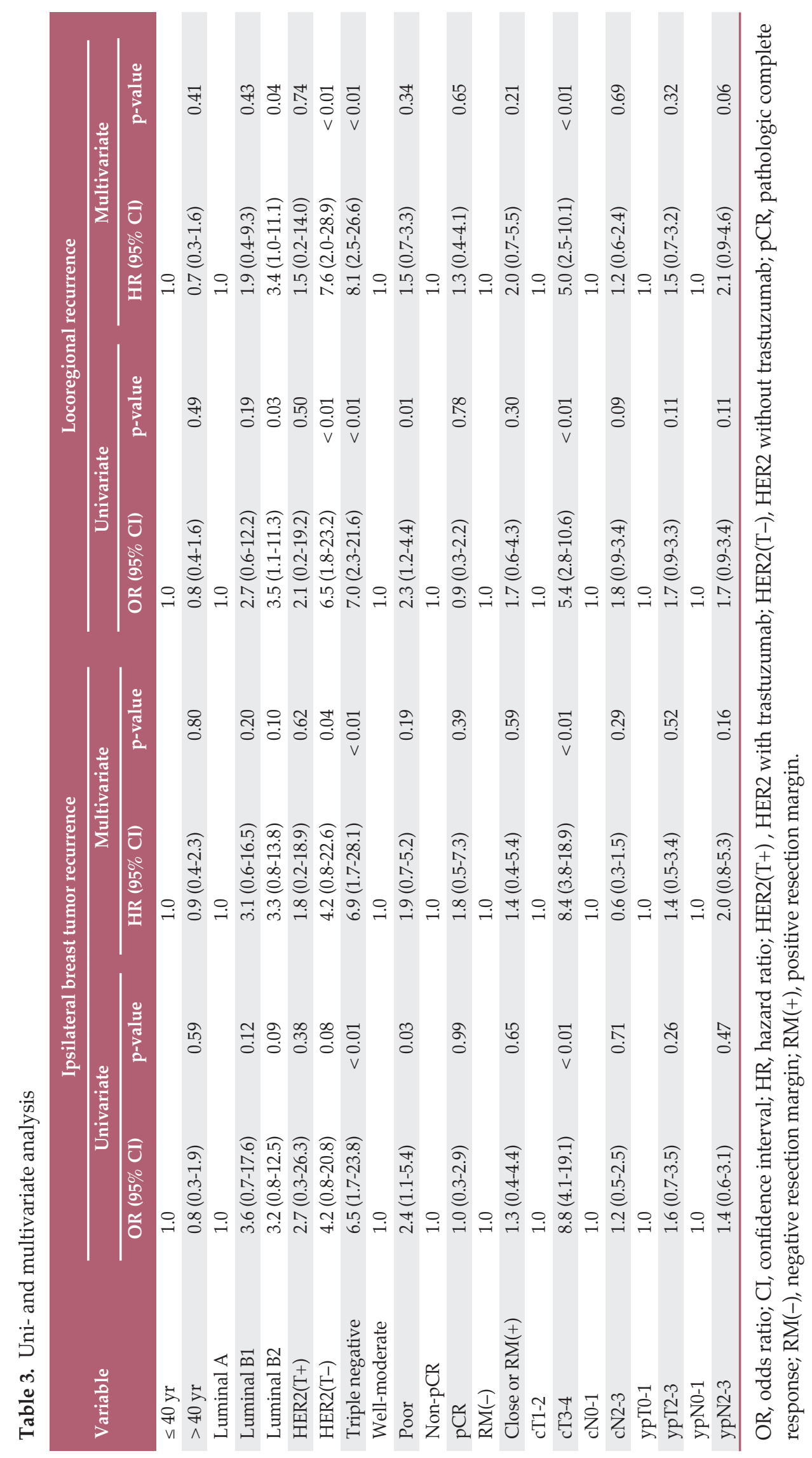




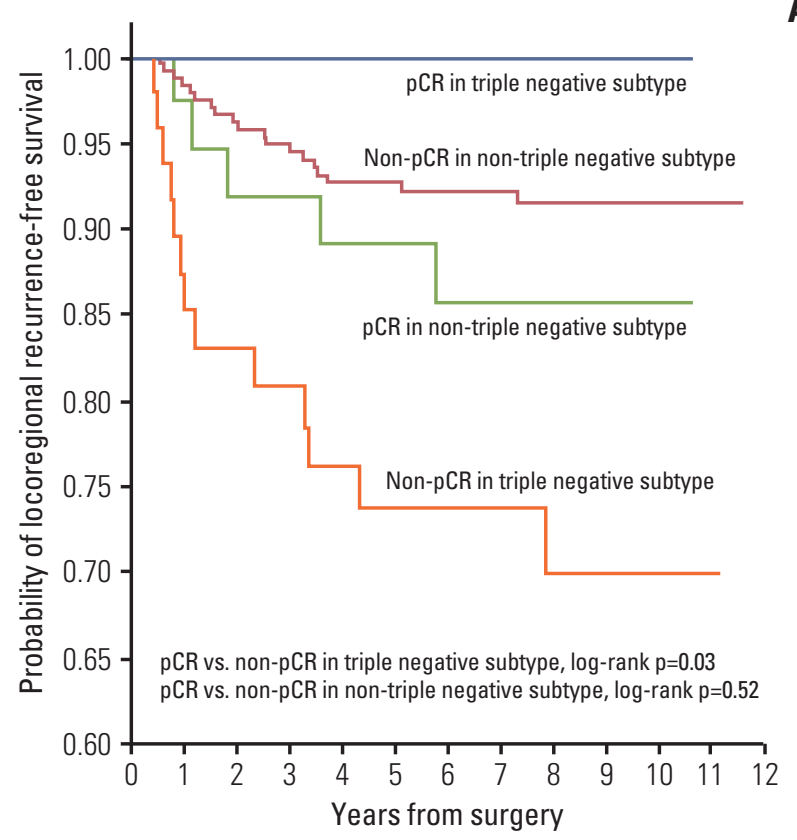

A

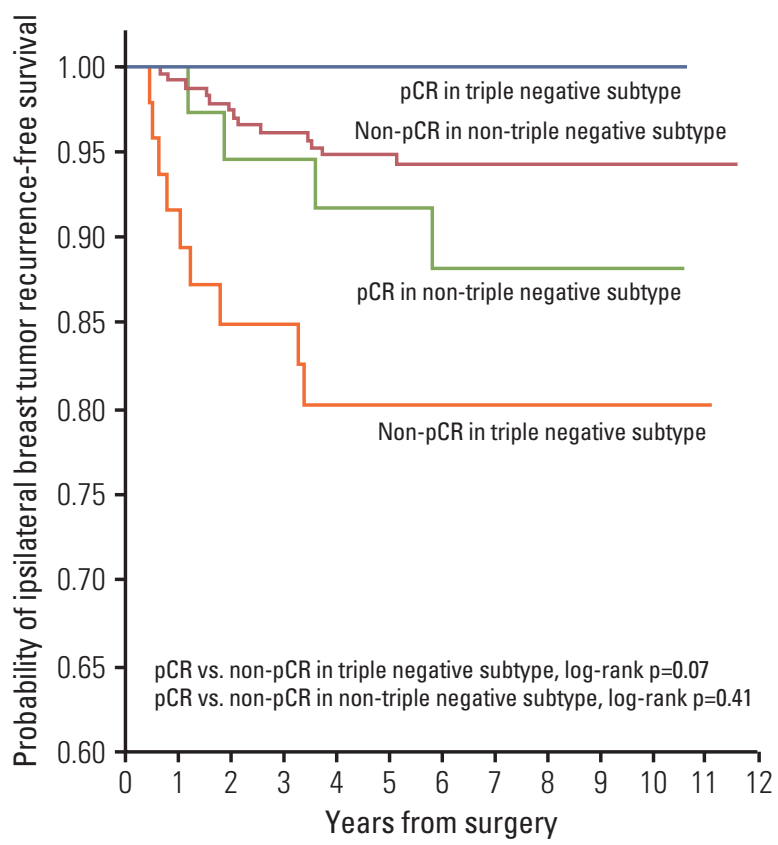

Fig. 2. Kaplan-Meier plots of locoregional recurrence-free survival (A) and ipsilateral breast tumor recurrence-free survival (B) by pathological complete response (pCR) versus a non-pCR in non-triple negative and triple negative subgroup patients.

did not affect LRR or IBTR regardless of subtype, while Caudle et al. [25] reported that patients achieving a pCR had similar LRR rates among subtypes.

However, our study had several limitations. First, the analysis was performed retrospectively. A second limitation was the modest number of patients evaluated; categorization according to the six subtypes resulted in a small number of patients in some subtypes, including HER2 $(\mathrm{T}+)$, luminal B1, and HER2(T-) patients. Therefore, these findings should be confirmed in a larger prospective study in the future.

\section{Conclusion}

In conclusion, we demonstrated that the TN and HER2 subtypes predicted higher rates of IBTR and LRR after NAC followed by BCT. Among the non-TN subtype patients, pCR was not predictive of better IBTR or LRR. However, among the TN subtype patients, a pCR to NAC was a predictor of better LRR control. The use of trastuzumab influenced IBTR and LRR in patients of the HER2 subtype. Taken together, a novel locoregional treatment strategy to decrease IBTR and LRR such as mastectomy instead of BCT in TN subtype patients with non-pCR to NAC deserves further investiga- tion. Improvements in systemic therapy, investigation of radiosensitizing agents, radiation dose escalation, and other new techniques may prove to be important.

\section{Conflicts of Interest}

Conflict of interest relevant to this article was not reported.

\section{Acknowledgments}

This work was supported by Research Resettlement Fund for the new faculty of Seoul National University. 


\section{References}

1. Schwartz GF, Birchansky CA, Komarnicky LT, Mansfield CM, Cantor RI, Biermann WA, et al. Induction chemotherapy followed by breast conservation for locally advanced carcinoma of the breast. Cancer. 1994;73:362-9.

2. van der Hage JA, van de Velde CJ, Julien JP, Tubiana-Hulin M, Vandervelden C, Duchateau L. Preoperative chemotherapy in primary operable breast cancer: results from the European Organization for Research and Treatment of Cancer trial 10902. J Clin Oncol. 2001;19:4224-37.

3. Rastogi P, Anderson SJ, Bear HD, Geyer CE, Kahlenberg MS, Robidoux A, et al. Preoperative chemotherapy: updates of National Surgical Adjuvant Breast and Bowel Project Protocols B-18 and B-27. J Clin Oncol. 2008;26:778-85.

4. Mieog JS, van der Hage JA, van de Velde CJ. Neoadjuvant chemotherapy for operable breast cancer. Br J Surg. 2007; 94:1189-200.

5. Min SY, Lee SJ, Shin KH, Park IH, Jung SY, Lee KS, et al. Locoregional recurrence of breast cancer in patients treated with breast conservation surgery and radiotherapy following neoadjuvant chemotherapy. Int J Radiat Oncol Biol Phys. 2011;81:e697-705.

6. Perou CM, Sorlie T, Eisen MB, van de Rijn M, Jeffrey SS, Rees $\mathrm{CA}$, et al. Molecular portraits of human breast tumours. Nature. 2000;406:747-52.

7. Sorlie T, Tibshirani R, Parker J, Hastie T, Marron JS, Nobel A, et al. Repeated observation of breast tumor subtypes in independent gene expression data sets. Proc Natl Acad Sci U S A. 2003;100:8418-23.

8. Brenton JD, Carey LA, Ahmed AA, Caldas C. Molecular classification and molecular forecasting of breast cancer: ready for clinical application? J Clin Oncol. 2005;23:7350-60.

9. Carey LA, Perou CM, Livasy CA, Dressler LG, Cowan D, Conway $\mathrm{K}$, et al. Race, breast cancer subtypes, and survival in the Carolina Breast Cancer Study. JAMA. 2006;295:2492-502.

10. Nguyen PL, Taghian AG, Katz MS, Niemierko A, Abi Raad RF, Boon WL, et al. Breast cancer subtype approximated by estrogen receptor, progesterone receptor, and HER-2 is associated with local and distant recurrence after breast-conserving therapy. J Clin Oncol. 2008;26:2373-8.

11. Albain KS, Barlow WE, Shak S, Hortobagyi GN, Livingston RB, Yeh IT, et al. Prognostic and predictive value of the 21-gene recurrence score assay in postmenopausal women with node-positive, oestrogen-receptor-positive breast cancer on chemotherapy: a retrospective analysis of a randomised trial. Lancet Oncol. 2010;11:55-65.

12. Mamounas EP, Tang G, Fisher B, Paik S, Shak S, Costantino $\mathrm{JP}$, et al. Association between the 21-gene recurrence score assay and risk of locoregional recurrence in node-negative, estrogen receptor-positive breast cancer: results from NSABP B-14 and NSABP B-20. J Clin Oncol. 2010;28:1677-83.

13. Lee KS, Ro J, Lee ES, Kang HS, Kim SW, Nam BH, et al. Primary systemic therapy with intermittent weekly paclitaxel plus gemcitabine in patients with stage II and III breast cancer: a phase II trial. Invest New Drugs. 2010;28:83-90.
14. Lee KS, Ro J, Nam BH, Lee ES, Kwon Y, Kwon HS, et al. A randomized phase-III trial of docetaxel/capecitabine versus doxorubicin/cyclophosphamide as primary chemotherapy for patients with stage II/III breast cancer. Breast Cancer Res Treat. 2008;109:481-9.

15. Allred DC, Harvey JM, Berardo M, Clark GM. Prognostic and predictive factors in breast cancer by immunohistochemical analysis. Mod Pathol. 1998;11:155-68.

16. Wolff AC, Hammond ME, Hicks DG, Dowsett M, McShane LM, Allison KH, et al. Recommendations for human epidermal growth factor receptor 2 testing in breast cancer: American Society of Clinical Oncology/College of American Pathologists clinical practice guideline update. J Clin Oncol. 2013; 31:3997-4013.

17. Dowsett M, Nielsen TO, A'Hern R, Bartlett J, Coombes RC, Cuzick J, et al. Assessment of Ki67 in breast cancer: recommendations from the International Ki67 in Breast Cancer working group. J Natl Cancer Inst. 2011;103:1656-64.

18. Goldhirsch A, Wood WC, Coates AS, Gelber RD, Thurlimann B, Senn HJ, et al. Strategies for subtypes: dealing with the diversity of breast cancer: highlights of the St. Gallen International Expert Consensus on the Primary Therapy of Early Breast Cancer 2011. Ann Oncol. 2011;22:1736-47.

19. Stuart-Harris R, Caldas C, Pinder SE, Pharoah P. Proliferation markers and survival in early breast cancer: a systematic review and meta-analysis of 85 studies in 32,825 patients. Breast. 2008;17:323-34.

20. Sorlie T, Perou CM, Tibshirani R, Aas T, Geisler S, Johnsen H, et al. Gene expression patterns of breast carcinomas distinguish tumor subclasses with clinical implications. Proc Natl Acad Sci U S A. 2001;98:10869-74.

21. Noh JM, Kim J, Cho DY, Choi DH, Park W, Huh SJ. Exome sequencing in a breast cancer family without BRCA mutation. Radiat Oncol J. 2015;33:149-54.

22. Arvold ND, Taghian AG, Niemierko A, Abi Raad RF, Sreedhara M, Nguyen PL, et al. Age, breast cancer subtype approximation, and local recurrence after breast-conserving therapy. J Clin Oncol. 2011;29:3885-91.

23. Vargo JA, Beriwal S, Ahrendt GM, Soran A, Johnson RR, McGuire K, et al. Molecular class as a predictor of locoregional and distant recurrence in the neoadjuvant setting for breast cancer. Oncology. 2011;80:341-9.

24. Meyers MO, Klauber-Demore N, Ollila DW, Amos KD, Moore DT, Drobish AA, et al. Impact of breast cancer molecular subtypes on locoregional recurrence in patients treated with neoadjuvant chemotherapy for locally advanced breast cancer. Ann Surg Oncol. 2011;18:2851-7.

25. Caudle AS, Yu TK, Tucker SL, Bedrosian I, Litton JK, Gonzalez-Angulo AM, et al. Local-regional control according to surrogate markers of breast cancer subtypes and response to neoadjuvant chemotherapy in breast cancer patients undergoing breast conserving therapy. Breast Cancer Res. 2012;14:R83.

26. Esserman LJ, Berry DA, Cheang MC, Yau C, Perou CM, Carey $\mathrm{L}$, et al. Chemotherapy response and recurrence-free survival 
in neoadjuvant breast cancer depends on biomarker profiles: results from the I-SPY 1 TRIAL (CALGB 150007/150012; ACRIN 6657). Breast Cancer Res Treat. 2012;132:1049-62.

27. Esserman LJ, Berry DA, DeMichele A, Carey L, Davis SE, Buxton $\mathrm{M}$, et al. Pathologic complete response predicts recurrencefree survival more effectively by cancer subset: results from the I-SPY 1 TRIAL--CALGB 150007/150012, ACRIN 6657. J
Clin Oncol. 2012;30:3242-9.

28. Yoo C, Ahn JH, Jung KH, Kim SB, Kim HH, Shin HJ, et al. Impact of immunohistochemistry-based molecular subtype on chemosensitivity and survival in patients with breast cancer following neoadjuvant chemotherapy. J Breast Cancer. 2012; 15:203-10. 